\title{
Relations Between Big Five Personality Characteristics and Perceived Support in Adolescents' Families
}

\author{
Susan J. T. Branje \\ Utrecht University
}

\author{
Cornelis F. M. van Lieshout \\ University of Nijmegen
}

\author{
Marcel A. G. van Aken \\ Utrecht University
}

\begin{abstract}
The authors investigated the longitudinal relations between family members' Big Five personality factors and perceived support. Members of 285 two-parent families with 2 adolescent children judged their own and other family members' Big Five factors and the support perceived from the other members on 3 occasions at 12-month intervals. The Big Five factor Agreeableness was particularly related to perceived support. Changes in individuals' Big Five factors were linked to changes in the support they perceived themselves but even more to changes in the support that other family members perceived from them. Results are consistent with the parallel continuities hypothesis: Individual characteristics will be stable when there is stability in the supportive environment, but when the environment is changing, personality tends to change in the same direction, and vice versa.
\end{abstract}

An individual's personality characteristics may influence the quality of their relationships, relationship quality may influence personality, and both personality and relationships may be affected by other factors. In recent decades, the transactional character of relations between personality and family relationships has been emphasized (Bell \& Chapman, 1986; Dunn, 1997; Halverson \& Wampler, 1997; Lollis \& Kuczynski, 1997; Maccoby, 1984; Sameroff, 1983). That is, family members are assumed to develop in a continuous process of transactions, in which personality and relationship characteristics may influence each other reciprocally.

The focus of this study was on the associations between the individual's personality characteristics and family relationships in families with adolescent children. Identifying how changes in the different Big Five personality characteristics are linked to changes in relationships is important because the rapid physiological and psychological changes during adolescence may present challenges for both adolescents and their parents. All members of the family have to renegotiate their interrelationships, attempting to maintain supportive relationships while at the same time respecting the

Susan J. T. Branje, Department of Child and Adolescent Studies, Utrecht University, Utrecht, the Netherlands; Cornelis F. M. van Lieshout, Department of Developmental Psychology, University of Nijmegen, Nijmegen, the Netherlands; Marcel A. G. van Aken, Department of Developmental Psychology, Utrecht University.

This research (Technologie Vergrijzing Werk Familie-MultiActorMultiMethode) was supported by grants from the Faculty of Social Sciences, University of Nijmegen, and Utrecht University. The Netherlands Organization for Scientific Research (NWO) is gratefully acknowledged for partly funding this research project by means of Grant 575-26-001.

Correspondence concerning this article should be addressed to Susan J. T. Branje, Department of Child and Adolescent Studies, Utrecht University, P.O. Box 80140, 3508 TC Utrecht, the Netherlands. E-mail: s.branje@fss.uu.nl growing individuality and autonomy of the adolescents. Most families will deal adequately with these tasks, but for a minority of families adolescence may be a stressful phase not only for the adolescents but also for their parents. When family members cannot handle these tasks adequately and their relationships deteriorate, or when they do handle these tasks adequately and their relationships ameliorate, this can subsequently lead to changes in personality factors. Therefore, we expect that during this life period the changes in personality characteristics of family members, and relationship characteristics of family dyads, may affect each other.

We investigated the longitudinal relations between the Big Five personality factors and a specific element of relationship experience-perceived support. This enabled us to examine whether there is evidence for systematic change and individual variability in change in the Big Five factors and perceived support of family members during the period of adolescence, and also how initial levels and changes of the Big Five factors are related to initial levels and changes in perceived support in dyadic family relationships. We examined the longitudinal relations between all Big Five factors and perceived support within all dyadic family relationships in families with adolescent children by modeling latent growth curves that represent intraindividual changes in Big Five factors and perceived support and interindividual differences in these changes. The Big Five factors of both relationship partners are likely to simultaneously influence their dyadic relationship (Robins, Caspi, \& Moffitt, 2000, 2002). Therefore, we distinguish two types of relations between Big Five factors and relational support in the dyadic family relationships: intrapersonal relations and interpersonal relations (see Caughlin, Huston, \& Houts, 2000). Intrapersonal relations describe the relation of the individual's Big Five factors with that individual's own perceived support. Interpersonal relations describe the relation of the individual's Big Five factors with the partner's perception of support. 


\section{Big Five Factors Within the Family Context}

When studying associations between the Big Five factors and perceived support within family relationships, the question that arises is which of the Big Five factors are most related to support perceptions in the family context. Evidence for both intrapersonal and interpersonal relations with relationship quality in various relationships has been reported for each of the Big Five factors in one or more studies (Asendorpf \& van Aken, 2003; Asendorpf \& Wilpers, 1998; Cutrona, Hessling, \& Suhr, 1997; Karney \& Bradbury, 1995; Lakey, Ross, Butler, \& Bentley, 1996; McCrae, Stone, Fagan, \& Costa, 1998; Neyer \& Asendorpf, 2001; Russell, Booth, Reed, \& Laughlin, 1997; Shaver \& Brennan, 1992; Watson, Hubbard, \& Wiese, 2000). Individuals who are more extravert, agreeable, conscientious, emotionally stable, and open reported more perceived relational support or relationship satisfaction themselves and also were perceived as more supportive by their relationship partners. Many of these studies included marital relationships and found the Extraversion and Emotional Stability factors of the relationship partners to be mostly related to the quality of the relationship in these relationships (see Cutrona et al., 1997; Shaver \& Brennan, 1992; Watson et al., 2000). However, most of these studies did not include all of the Big Five factors, and the focus was mostly on the influence of only intra- or interpersonal relations.

We investigate both intra- and interpersonal relations over time between the Big Five personality factors and perceived support in all dyadic family relationships of families with 11- to 15-year-old adolescents. We hypothesize that the Big Five factors Agreeableness and Conscientiousness are especially relevant for family relationships. Agreeableness reflects the interrelatedness of one's interests with those of the other in a relationship and one's motives for maintaining positive relationships with others (JensenCampbell \& Graziano, 2001; Van Lieshout, 2000). Conscientiousness is related to the performance of tasks and the fulfillment of mutual obligations (Conner \& Abraham, 2001; Hogan \& Ones, 1997; Van Lieshout, 2000). Relationships in families with adolescents can be characterized by the extent to which they are warm and responsive (Bloom, 1985; Holmbeck, Paikoff, \& BrooksGunn, 1995; Olson, 1986) and by the extent to which the dyadic partners fulfill tasks and responsibilities. For example, adolescents are thought to learn individual and social responsibility through their involvement in household tasks (Bowes, Flanagan, \& Taylor, 2001), and parent-adolescent conflicts often center on day-to-day issues such as responsibilities and chores (Laursen, 1995). Conscientiousness enhances the extent to which family members keep their promises, stick to agreements, and attend to their chores, and this reflects the efficiency of family functioning. Jensen-Campbell and Graziano (2001) reported Agreeableness and Conscientiousness to be related to adolescents' interpersonal conflicts with parents, siblings, and peers, and Robins, John, and Caspi (1994) found that low levels of both Agreeableness and Conscientiousness in adolescent boys were related to antisocial behavior. Therefore, we hypothesize that perceived support and changes in support within family relationships, especially in the parent-child relationship and in the sibling relationship, will reveal the strongest relations to the Big Five factors Agreeableness and Conscientiousness. On the basis of research showing that Extraversion and Emotional Stability are mostly related to the quality of marital relationships, we expect Extraversion and Emotional Stability to be more important in the relationship between father and mother than in the other family relationships.

\section{Big Five-Perceived Support Relations}

We investigate changes in the Big Five personality factors and support perceptions in members of families with adolescent children, as well as links between these changes in Big Five factors and perceived support. Relations between family members' Big Five characteristics and perceived support can be assessed by examining three types of relations: contemporary relations, overtime relations, and concomitant change.

\section{Contemporary Relations}

Individual differences in Big Five factors are found to be fairly stable, which means that individuals are consistent over time in the way they characteristically relate to the environment in different settings (Caspi, 1998, 2000; Caspi \& Roberts, 1999, 2001; Roberts, Caspi, \& Moffitt, 2001; Roberts \& DelVecchio, 2000; Shiner, Tellegen, \& Masten, 2001; Stein, Newcomb, \& Bentler, 1986). Perceived support in family relationships seems to be moderately stable as well (e.g., Manetti \& Schneider, 1996; Weigel, Devereux, Leigh, \& Ballard-Reisch, 1998). Therefore, it is likely that reciprocal influences between the Big Five factors of the relationship partners and their support perceptions have been established early in the relationship (i.e., when the relationship was formed). Indeed, in marital relationships, Huston, Caughlin, Houts, Smith, and George (2001) found most support for an "enduring dynamics" model, in which interpersonal patterns manifest themselves early in a relationship and are maintained throughout the course of the relationship.

\section{Over-Time Relations}

Although links between the Big Five factors and perceived support within family relationships may have been established early in the relationship, reciprocal effects during the period of adolescence may still occur. The causal direction of effects in the relation between Big Five factors and perceived support is not entirely clear. Personality is often regarded as an innate temperament, governed by internal, biological mechanisms, and not susceptible to change in response to the influence of the environment (e.g., McCrae et al., 2000). Subsequently, Big Five factors are thought more likely to influence relationship qualities than vice versa, because the effects of the more stable Big Five factors are also more stable and accumulate over time. This is consistent with findings that, in friendship relationships and romantic relationships of young adults, personality characteristics are more predictive of relationship experiences than relationship experiences are predictive of personality characteristics (Asendorpf \& van Aken, 2003; Neyer \& Asendorpf, 2001; Robins, Caspi, \& Moffitt, 2002). In contrast, within a contextual approach to personality (Lewis, 1999), the importance of life changes and role transitions on personality development is emphasized, suggesting that personality is fluid and prone to change as a result of environmental factors. Family relationships are so important for individual development (Collins, Maccoby, Steinberg, Hetherington, \& Bornstein, 2000; Reis, Collins, \& Berscheid, 2000) that changes in these relationships could be expected to affect Big Five factors. However, 
studies that address these issues are sparse (see Halverson \& Wampler, 1997).

To our knowledge, only three studies have used integrative longitudinal models to analyze associations between the Big Five factors and support perceptions, thereby controlling for contemporary correlations between Big Five factors and relationships and the stability of those Big Five factors (Asendorpf \& van Aken, 2003; Asendorpf \& Wilpers, 1998; Neyer \& Asendorpf, 2001). They found that interindividual differences in Big Five factors predict changes in support perceptions but that relationship characteristics did not predict changes in Big Five factors. Relationship qualities are more likely to fluctuate, and the effects of different relationship qualities and different relationships on family members' Big Five characteristics may even be contradictory. Therefore, we hypothesize that over-time relations between Big Five factors and perceived relational support in adolescents' families will appear mainly from Big Five factors to perceived support.

\section{Concomitant Change}

Besides contemporary and over-time relations, changes in individual family members' Big Five Factors may be reciprocally related to their concomitant changes in perceived support, both intrapersonally and interpersonally. Those family members who change in their Big Five factors are expected to simultaneously change in the support they perceive or that is perceived from them in dyadic family relationships, because individuals are apt to change their behavior and adjust to the changed environment. According to the parallel continuities hypothesis, individual behavior will be stable when there is concomitant stability in the environment, especially in the parenting or family system (Caspi, 1993; Halverson \& Wampler, 1997; Patterson \& Bank, 1989), but if either of the two changes, the other part may concomitantly change too. Consequently, we expect changes in Big Five factors and support to accompany each other.

All in all, we hypothesize that (a) perceived support in adolescent family relationships is mostly related to family members' Agreeableness and Conscientiousness, especially in the relationships involving adolescents; (b) individual family members will change in Big Five factors or perceived support during the period of adolescence; (c) over-time relations between Big Five factors and perceived support during adolescence will be found more from Big Five factors to perceived support than vice versa; and (d) changes in Big Five factors and support accompany each other both intrapersonally and interpersonally. We subsequently used growth curve analyses to examine these relations between family members' Big Five factors and perceived support.

\section{Method}

\section{Participants}

The participants were 288 middle-class two-parent Dutch families with at least two adolescent children. The participants were recruited for a larger study, the Nijmegen Family and Personality Study (Haselager \& van Aken, 1999). A representative selection of 23 municipalities throughout the Netherlands provided lists of families with at least two adolescents between the ages of 11 and 15 years. After a mailing announcing the study, interviewers contacted families, verified that two of the children in the family met the age criteria (between 11 and 15 years), and invited families to participate until the required number of participants was attained. In the end, $44 \%$ of families contacted participated in the study. Some frequent reasons for not participating were a lack of interest in the topic of the project, a family member not wanting to cooperate, or the family not matching all the sample criteria. The two parents and two target adolescents from each family participated in the study. The average ages for the fathers $(n=288)$ and mothers $(n=288)$ were 43.9 and 41.7 years (ranging from 34.0 to 56.1 and 34.0 to 51.2 , respectively). The older adolescents ( 144 boys, 144 girls) were 14.5 years of age on average (ranging from 11.4 to 16.0 ); the younger adolescents (136 boys, 152 girls) were 12.4 years of age on average (ranging from 11.0 to 14.8 ).

\section{Procedure}

Families participated in three measurement waves, at 12-month intervals starting in October 1997. In each wave, an interviewer visited the families at home and asked the mother, the father, and each of the two target adolescents to simultaneously complete a questionnaire. The presence of the interviewer encouraged complete responding and prevented collaboration among the family members as they completed the questionnaire. All of the participating family members evaluated themselves and each of the other participating family members on the Big Five factors and evaluated the level of perceived support from each of the other participating family members. That is, the adolescents evaluated the support perceived from the father, the mother, and the other sibling; the parents evaluated the support perceived from their partner, the older adolescent, and the younger adolescent. As part of the larger study, in each measurement wave, the two adolescents in the family were given a $\mathrm{CD}$ gift voucher after completion of the questionnaire. Following the completion of the third wave of measurement, five lottery prizes were distributed among families that had participated on all three occasions. Attrition rate was extremely low: Of the 288 families that started in the study, 285 participated in Wave 3.

\section{Measures}

Perceived relational support. Perceived support was measured using the Relational Support Inventory (RSI; Scholte, van Lieshout, \& van Aken, 2001). The inventory involves 27 questions representing four dimensions of perceived support each measured by six items on a 5-point Likert scale ranging from very untrue of this person (1) through sometimes untrue, sometimes true of this person (3) to very true of this person (5), and a more general feeling of acceptance measured by three items.

The first support dimension is perceived quality of information and assesses the quality of information and withholding of information (coded negatively). Examples of the items are "This person explains or demonstrates how I can make or do something" and "This person says things that are not true in order to get rid of me or to lead me astray" (-). The second support dimension is perceived respect for autonomy and assesses respect for autonomy and limit setting (-). For example, "This person allows me to solve problems on my own as much as possible but also provides help when I ask for it" and "This person makes decisions that I would like to make myself" (-). The third support dimension is perceived emotional support and assesses warmth as opposed to hostility (-). Sample items are "This person supports what I am doing" and "In this person's view, I can't do anything right: he/she is always criticizing me" (-). The fourth support dimension is perceived convergence of goals and assesses the perceived degree of convergence as opposed to divergence (-) of goals. Two sample items are "This person and I have the same opinions on the use of drugs, alcohol, or gambling" and "This person and I have many conflicts with regard to school achievement, the future, or career opportunities" (-). Acceptance measures a more general feeling of acceptance in the relationship, for example: "This person accepts me as I am."

We computed overall perceived support scores for each unilateral support perception by averaging the scores on the five support dimensions. For example, the overall support that mothers perceive from fathers was computed by averaging the support that mothers perceive from fathers on each of the five support dimensions. Reliabilities of these mean support 
scores for each of the 12 unilateral support perceptions were on average $\alpha=.82$ with a range of $\alpha=.80$ to $\alpha=.87$.

Big Five factors. A Dutch adaptation (Gerris et al., 1998) of 30 adjective Big Five factors markers selected from Goldberg (1992) was used to have family members judge their own personalities and the personalities of the other three participating family members. The participants rated the 30 adjectives on a 7-point Likert scale ranging from 1 (very untrue of this person) through 4 (sometimes untrue, sometimes true of this person) to 7 (very true of this person). All the Big Five factors were rated: Extraversion, Agreeableness, Conscientiousness, Emotional Stability, and Openness to Experience. Extraversion assesses the extent to which the person actively engages the world or avoids intense (social) experience (e.g., talkative or shy). Agreeableness assesses the interpersonal nature of the person and can range from warm and committed to others (e.g., friendly) to antagonistic. Conscientiousness assesses the degree of organization, persistence, and motivation during the fulfillment of goal-directed task behaviors (e.g., meticulous or careless). Emotional Stability assesses the extent to which the person is emotionally stable or plagued by unpleasant experiences and distressing emotions (e.g., nervous). Openness to Experience assesses the depth, complexity, and quality of a person's mental and experiential life along with the flexibility of his or her information processing (e.g., versatile). The internal consistencies (Cronbach's alpha) for the different dimensions of Big Five factors rated by different family members ranged from .81 to .92 for all judgments of fathers' Big Five factors, from .76 to .93 for all judgments of mothers' Big Five factors, from .68 to .90 for all judgments of older adolescents' Big Five factors, and from .63 to .87 for all judgments of younger adolescents' Big Five factors.

Earlier research using the social relations model has shown that agreement in family members' judgments of each other's Big Five personality characteristics is limited (Branje, van Aken, van Lieshout, \& Mathijssen, 2003): On average only $11 \%$ of the variance in individual personality factors could be explained by target effects (i.e., the agreement in the judgments provided by different family members on a particular target individual). Only interindividual differences in Conscientiousness could be primarily attributed to differences in the personality that all family members perceive of a particular family member (for this factor, $24 \%$ of the variance could be explained by agreement among family members).

We considered various options for using personality assessments provided by different people to prevent the effects of shared informant variance in the personality and support ratings. Operationalizing personality by three instead of four judgments (thereby removing the judgment of the family member who judged perceived support) would lead to four different sets of personality scores for each family member's Big Five factors over the different dyadic relationships. For example, in the relation between father and the oldest child we would use the judgment of mother and the two children for intrapersonal links and the judgments of father, mother, and sibling for interpersonal links. Consequently, we would need to estimate four univariate growth curves for each family member's personality characteristics, based on these four different sets of ratings. This would complicate the interpretation of results because differences in results could be due to the use of different raters (i.e., differences in results might reflect differences in judgments of parents vs. children). In addition, using a selection of judgments would prevent us from using growth curve models in which we estimate intra- and interpersonal effects at the same time. Estimating these effects at the same time is important in controlling for dyadic interdependence (Griffin \& Gonzalez, 1995; Kenny, 1995, 1996; Kenny \& Cook, 1999). That is, family members may be nonindependent in their characteristics. Failing to control for this nonindependence may bias the tests of significance of the effects that partners have on each other's behavior. Excluding both informants of a dyad from the personality measures for both members of the dyad is a similar but even weaker approach, which would lead to a larger loss of reliability and a stronger variation of the personality operationalization across dyads. Because of these difficulties in removing bias, we reasoned that it was best to equally enhance intrapersonal and interpersonal effects. To acquire robust and consistent
Big Five factor judgments across family dyads, we computed Big Five factors scores by averaging all the family members' judgments of a particular target family member (i.e., the self-judgment and three judgments by the other family members). In this way, we were able to estimate the effects of both dyadic partners while controlling for dyadic interdependency, and intrapersonal and interpersonal effects were equally enhanced.

To examine possible effects of rater bias, we computed Wave 1 correlations between relational support and each family member's judgment of each member's personality and compared the correlations for the different judgments. Results showed that interpersonal correlations were indeed highest for judgments of the same informant (e.g., mothers' perception of fathers' Agreeableness had the highest correlation to mothers' perception of fathers' support, $r=.53$ ). However, intrapersonal effects did not seem to be inflated by a rater bias (e.g., fathers' perception of fathers' Agreeableness was similarly related to fathers' perception of mothers' support as the adolescents' perception of fathers' Agreeableness, $r=.08$ vs. $r=.24$ and $r=.15$ ). Furthermore, as the example shows, self-reported personality was often less related to the support perceived from them than otherreported personality. This may reflect an underestimation of one's own effects on others. Therefore, using all reports (including the self-report) may correct for the rater bias in interpersonal relations. In addition, we computed personality scores based on three of the four judgments and correlated these scores with perceived support. Results hardly differed from the correlations based on the four judgments of personality. All in all, using a selection of judgments does not change the pattern of results to any great extent.

We explored the reliabilities of the averaged Big Five factors judgments by computing alphas on the 24 items ( 6 items $\times 4$ judges) constituting the averaged judgments of the Big Five factors. The resulting alphas were on average .85 , with a range of .82 to .93 .

\section{Statistical Analysis}

Latent growth curve modeling (LGM) was used to examine changes in Big Five factors and perceived support, as well as the relations between the Big Five factors and perceived support across time. The focus in LGM is on latent factors that are thought to represent the growth trajectories giving rise to repeated measures over time, while controlling for the effects of measurement error (Duncan, Duncan, \& Strycker, 2001; Hamagami \& McArdle, 2001; McArdle \& Bell, 2000; Mehta \& West, 2000; Muthen \& Curran, 1997). Changes in mean levels as well as changes in individual differences of personality characteristics and support perceptions can be examined using the LGM method.

In the present study, LGM analyses were performed in two steps. In the first step, univariate LGMs were fitted to the family members' Big Five factors and their dyadic support perceptions to determine the form of the growth trajectory that most adequately described intraindividual changes and interindividual differences in these changes in each Big Five factor and support perception. In the second step, we used these unobserved components of change and examined the longitudinal relations between the Big Five factors and support perceptions in dyadic family relationships in multivariate LGMs.

The model presented in Figure 1 represents the univariate latent growth models that were estimated in the present study ( 12 for perceived relational support and 20 for each family member's Big Five characteristics). The variables T1 (Time 1) to T3 (Time 3) refer to the dependent variable (e.g., older adolescents' perceived support from fathers) measured annually for 3 years. The $\varepsilon s$ represent error variances in the repeated measures. To retain enough degrees of freedom, error variances were set equal. The first latent factor is labeled the intercept and corresponds to the initial status of the dependent variable: the support that older adolescents perceive from fathers at Time 1, for example. The intercept is a constant for any individual across time that represents information about the mean, represented by $\mu_{\mathrm{I}}$, and the variance, represented by $\sigma_{\mathrm{I}}^{2}$, of the collection of individual intercepts. The loadings of all three measured variables on the intercept factor are constrained to 1 . 


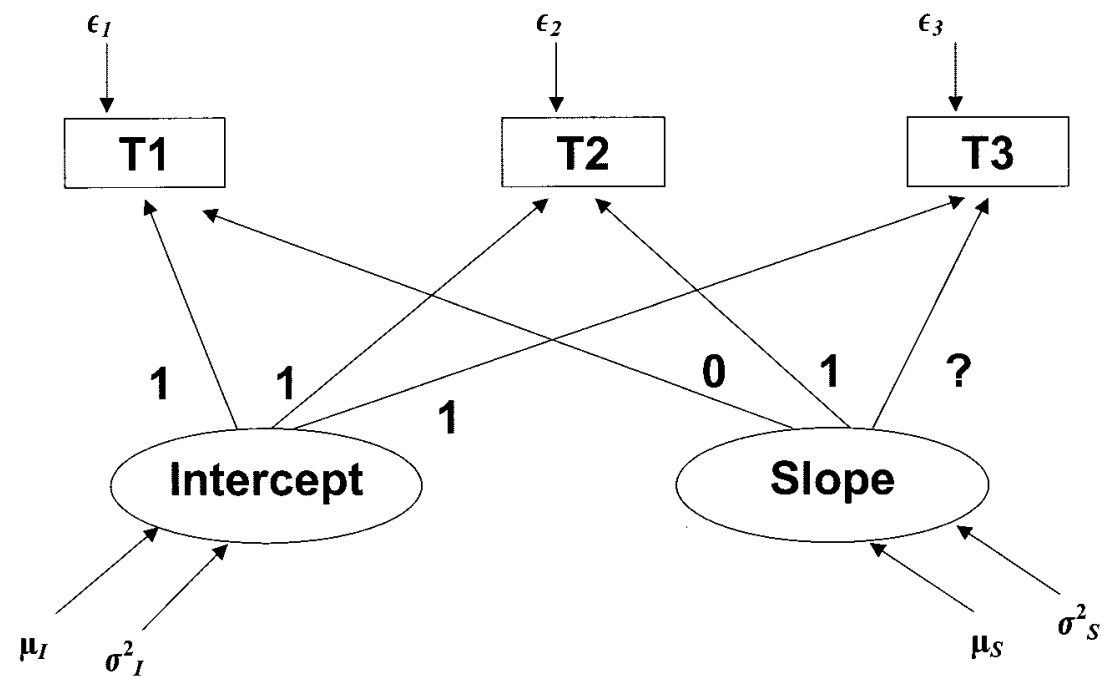

Figure 1. The estimated univariate growth curve models. T1, T2, and T3 refer to the dependent variable measured annually for 3 years $(\mathrm{T} 1=$ Time $1 ; \mathrm{T} 2=$ Time 2 ; $\mathrm{T} 3=$ Time 3$)$. The epsilons $(\varepsilon \mathrm{s})$ represent error variances in the repeated measures. ? = the freely estimated loading at $\mathrm{T} 3$.

The second factor, labeled slope, represents the rate of change (increase or decrease) in perceived support or Big Five factor over the period of the study (i.e., from Time 1 to Time 3). The slope factor also has a mean, $\mu_{S}$, and a variance, $\sigma_{S}^{2}$. At least two slope factor loadings must be fixed to two different values to identify the model (Meredith \& Tisak, 1990). We specified a change trajectory by fitting a model with the slope factor loadings for Time 1 and Time 2 being 0 and 1, with the factor loading for Time 3 freely estimated. Freely estimating the third parameter enables us to model an unspecified trajectory in which the shape of the trajectory is determined by the data (i.e., as in Figure 1; Muthen, 1991; Rao, 1958). We chose to model an unspecified model, because we were interested in assessing the actual change curve, and this would allow for differences in changes from Time 1 to Time 2 and from Time 2 to Time 3 . If the parameter for Time 3 is exactly 2 , this would indicate strictly linear change. A value for this parameter larger than 2 would indicate increasing change, a value between 1 and 2 would indicate decreasing change, and a value smaller than 1 would point to curvilinear change.

\section{Multivariate Latent Growth Models}

Multivariate growth curve analyses were used to test our hypotheses regarding the relations between Big Five factors and perceived support. For each of the six family dyads, five multivariate growth curve models were estimated using LISREL (one for each Big Five factor). The estimated values of the intercept and slope factor means and variances resulting from the univariate models were fixed in the multivariate models. This meant that there were enough degrees of freedom to estimate all relations between personality and perceived support. All multivariate latent growth models assumed that within-informants errors were distributed randomly and uncorrelated across time.

In each model, we simultaneously estimated all possible correlations: the correlations among intercepts and among slopes and the correlations between intercepts and slopes. Figure 2 shows a model of the relations estimated in these growth curve models. Intrapersonal and interpersonal correlations between intercepts were estimated to examine contemporary correlations between personality and perceived support: Do individuals who score higher on a personality factor perceive more support from their family members, and are individuals who score higher on a personality factor perceived as more supportive by their family members? Intrapersonal and interpersonal correlations between slopes were estimated to examine correlated change: Are changes in the individual's personality factors related to changes in the support they perceive and in the support perceived from them? Moreover, we estimated the correlations between the intercepts and the slopes of the different variables. Again, we estimated intrapersonal and interpersonal correlations. Intrapersonal correlations among the intercepts and the slopes of the Big Five factors and perceived support were examined to explore whether individuals who change more over time in terms of perceived support or personality are initially characterized by higher or lower levels of perceived support or personality characteristics. We tested interpersonal correlations between the intercepts and the slopes of the Big Five factors and perceived support to examine whether the dyadic partners of individuals who initially score higher on perceived support or on a personality factor change more over time in perceived support or personality factors. We did not estimate the interpersonal correlations between perceived support intercepts and the partner's Big Five factor slopes, because we do not expect one individual's perceptions to influence another individual's Big Five factors.

All in all, we estimated contemporary correlations, over-time correlations, and correlated change between the Big Five factors and perceived support of family members in various dyadic relationships. These correlations were estimated both intrapersonally and interpersonally. To be able to present the nonsignificant estimates, nonsignificant paths were not removed from the model. This also implies that we did not try to optimize model fit.

A total of 120 over-time personality-support effects and 60 over-time support-personality effects were estimated. The estimation of this large number of effects could easily result in false positive findings resulting from Type I error. To avoid this, we regarded effects as significant only if the significance level was $p<.01$. In addition, we applied a Bonferroni correction. If no Bonferroni correction were to be applied we would have a $70.06 \%$ chance of finding one or more significant differences by chance alone in 120 tests. We needed to apply an alpha for each test of .00008 to bring the overall alpha level back to .01. Similarly, for 60 tests we needed to apply an alpha level of .00017.

LISREL 8.3 structural equation modeling software (Jöreskog \& Sörbom, 1996) was used for all latent growth models reported in this study. Cases with missing values were deleted listwise, resulting in a sample of $N=$ 270. To evaluate the fit of each growth model, we used Jöreskog and Sörbom's goodness-of-fit index (GFI), Bentler's (1990) comparative fit index (CFI), the nonnormed fit index (NNFI), and Steiger's (1990) root- 


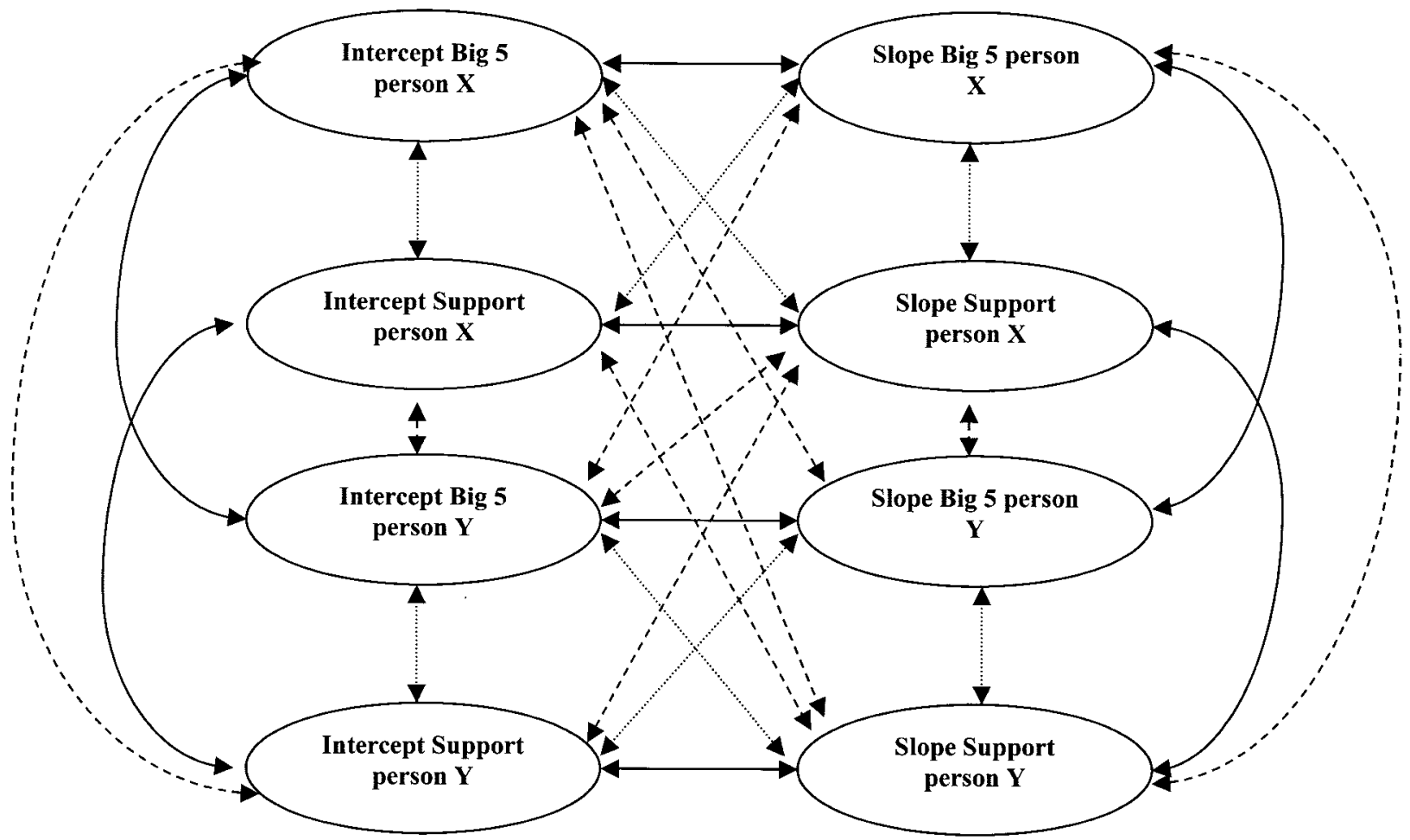

Figure 2. The estimated multivariate growth curve models: contemporary relations, intrapersonal and interpersonal effects, and correlated change. The double-headed curved arrows between the factors indicate that latent factors are allowed to covary. Fine-dotted arrows indicate intrapersonal effects; heavy-dotted arrows indicate interpersonal effects.

mean-square error of approximation (RMSEA). For values of GFI, CFI, and NNFI, the convention of above .95 was adopted here as an indication of good fit (Browne \& Cudeck, 1989, 1993; Hu \& Bentler, 1999). RMSEA values up to .06 represent a close fit of the model and values up to .10 represent reasonable errors of approximation in the population.

\section{Results}

\section{Descriptive Statistics: Reliable Change in Big Five Personality Factors and Perceived Support}

Before we estimated latent growth curve models, we first calculated the reliable change index (RCI; Christensen \& Mendoza, 1986; Jacobson \& Truax, 1991) to investigate whether individual family members could be identified who did exhibit reliable changes in Big Five personality factors or perceived relational support over a 2-year period (i.e., from the first to the third measurement wave; see Roberts et al., 2001). The RCI is computed by

$$
\mathrm{RC}=X_{3}-X_{1} / S_{\mathrm{diff}},
$$

where $X_{1}$ represents a person's score at Time $1, X_{3}$ represents that same person's score at Time 3 , and $S_{\text {diff }}$ is the standard error of difference between the two test scores, which can be computed using the standard error of measurement formula:

$$
S_{\text {diff }}=\left[2\left(S_{\mathrm{E}}\right)^{2}\right]^{1 / 2}=2^{1 / 2} S_{\mathrm{E}}
$$

The standard error of the difference score represents the spread of the distribution of change scores that would be expected if no actual change has occurred. RC scores smaller than -1.96 or larger than 1.96 are unlikely to occur without true change and are thus considered reliable. Furthermore, if individual level changes were random, then we would expect the distribution of RC scores to be normal, with approximately $2.5 \%$ below $-1.96,2.5 \%$ above 1.96 , and $95 \%$ of the participants remaining the same. That is, we would expect roughly $5 \%$ of the sample to reliably increase and decrease and $95 \%$ to remain unchanged. The key question concerning individual level change is thus whether or not it might be attributed to chance.

The RCIs showed that the vast majority of family members $(73.5 \%-91.5 \%)$ stayed the same over this 3-year period on any given Big Five factor and on perceived support, with a sizable minority showing change (see Table 1). The chi-square statistics in Table 1 show that for all Big Five factors and all dyadic support perceptions, the distribution of decreasers, nonchangers, and increasers differed significantly from the random-change pattern and could not therefore be attributed to chance.

On the whole, the percentage of individuals who reliably increased and who reliably decreased on personality over time was evenly distributed. Especially notable was the fact that $24 \%$ of the mothers reliably increased over time on Conscientiousness whereas the number of mothers who reliably decreased over time was at the chance level. On perceived support, the percentage of decreasers was mostly larger than the percentage of increasers. The 
Table 1

Percentage of Reliable Changers on Personality and Perceived Relational Support

\begin{tabular}{|c|c|c|c|c|c|c|c|c|}
\hline \multirow[b]{2}{*}{ Measure } & \multicolumn{2}{|l|}{ Father } & \multicolumn{2}{|l|}{ Mother } & \multicolumn{2}{|c|}{ Older child } & \multicolumn{2}{|c|}{ Younger child } \\
\hline & Increase/decrease & $\chi^{2}$ & Increase/decrease & $\chi^{2}$ & Increase/decrease & $\chi^{2}$ & Increase/decrease & $\chi^{2}$ \\
\hline Extraversion & $5.6 / 7.4$ & $39.99 *$ & $6.4 / 4.6$ & $22.89 *$ & $11.2 / 7.7$ & $123.74 *$ & $7.4 / 7.7$ & $61.13^{*}$ \\
\hline Agreeableness & $4.2 / 10.2$ & $73.14 *$ & $8.5 / 9.2$ & $95.89 *$ & $9.1 / 6.3$ & $69.87 *$ & $9.8 / 9.8$ & $128.76^{*}$ \\
\hline Conscientiousness & $5.3 / 5.6$ & $20.80 *$ & $24.0 / 2.5$ & $538.42 *$ & $14.4 / 11.6$ & $268.21 *$ & $12.3 / 9.1$ & $167.13^{*}$ \\
\hline Emotional Stability & $4.2 / 5.6$ & $15.09 *$ & $6.4 / 4.9$ & $24.83^{*}$ & $7.4 / 6.3$ & $45.88^{*}$ & $5.3 / 4.2$ & $12.64 *$ \\
\hline Openness to Experience & $6.7 / 3.5$ & $21.76^{*}$ & $8.5 / 2.5$ & $41.55^{*}$ & $6.7 / 5.3$ & $29.94 *$ & $5.3 / 3.2$ & $9.55^{*}$ \\
\hline Support from father & & & $3.6 / 14.2$ & $160.88^{*}$ & $8.8 / 17.5$ & $316.48^{*}$ & $6.8 / 6.8$ & $42.98^{*}$ \\
\hline Support from mother & $2.8 / 11.0$ & $83.80^{*}$ & & & $8.8 / 14.5$ & $218.09 *$ & $6.1 / 8.9$ & $63.52 *$ \\
\hline Support from older child & $6.7 / 11.0$ & $105.79 *$ & $4.3 / 11.7$ & $103.15^{*}$ & & & $13.9 / 7.1$ & $177.07 *$ \\
\hline Support from younger child & $5.3 / 13.8$ & $158.84^{*}$ & $5.3 / 12.5$ & $125.30^{*}$ & $10.9 / 11.6$ & $183.11 *$ & & \\
\hline
\end{tabular}

Note. Increase/decrease represents percentage increase and decrease, respectively, based on the Reliable Change Indices. The chi-square tested whether the observed distribution of changers and nonchangers differed from the expected distribution if change were random (i.e., 2.5\% decrease and increase, $95 \%$ remain the same). For all chi-square tests, $N$ s range from 280 to $285 ; d f=2$.

$* p<.05$

only relationship on which more individuals reported increases than decreases in support over time was younger adolescents' relationships with an older sibling.

When individual level change for each individual family member (i.e., fathers, mothers, older children, younger children) was examined across all Big Five factors, we discovered that $42 \%$ to $59 \%$ of the family members did not change on any Big Five factor over the 2-year period. Twenty percent to $29 \%$ of the family members significantly decreased over time and $19 \%$ to $36 \%$ significantly increased over time on at least one Big Five factor. When individual level change for each individual family member across perceived support from all three other family members was examined, we discovered that $61 \%$ to $71 \%$ of the family members did not change on perceived support in any of the three dyads over the 2 -year period. Fourteen percent to $24 \%$ of the family members revealed a significant decrease, and $9 \%$ to $17 \%$ revealed an increase in perceived support in at least one dyad.

It appears that quite a lot of family members do reveal reliable change in Big Five factors and perceived support, even over a 2-year period. About half of the individuals demonstrated reliable change on one or two Big Five factors or on perceived support from one or more family members.

\section{Univariate Latent Growth Models}

Univariate growth curve analyses for each family member's Big Five factors and dyadic support perceptions were used to test our hypotheses regarding change in Big Five factors and perceived support. Tables 2 and 3, respectively, contain the parameter estimates for the different univariate models for personality and perceived support. The fit indices of these models provided an acceptable to good fit to the data. For perceived relational support, chi-squares ranged from 0.88 to 10.15 , and a mean of 4.34 for models with 2 degrees of freedom $(N=270), p>.05$, GFI of .99 , the NNFI ranging from .97 to 1 with a mean of .99 , and the RMSEA ranging from .00 to .12 with a mean of .06 . For personality, chi-squares ranged from 0 to 18.29 , and a mean of 3.52 for models with 2 or 3 degrees of freedom $(N=270), p>.05$, GFI ranging from .96 to 1 with a mean of .99 , NNFI ranging from .95 to 1 with a mean of .99 , and the RMSEA ranging from 0 to .17 with a mean of .03 .
The significant mean estimates for the intercepts in the fifth column of Tables 2 and 3 show family members' initial mean scores on the Big Five factors and on perceived support; their significance only indicates that the scores significantly differed from zero (which is trivial for ratings on a 1-7 scale). As can be seen in the 6th column of Tables 2 and 3, the variance for the intercept factors was significantly different from zero for all support perceptions and personality scores, which indicates that there were systematic individual differences in family members' initial (Time 1) personality characteristics and support perceptions.

The Time 3 slope factor loadings are presented in the fourth column of Tables 2 and 3. In most cases the loadings were significantly different from 0 and usually had a value between 1 and 2 . This means that personality and perceived support were best described by a nonlinear trajectory in which personality and support changed from Time 1 to Time 3, with a smaller increase or

Table 2

Univariate Latent Growth Curve Results for Perceived Support in Family Dyads

\begin{tabular}{|c|c|c|c|c|c|}
\hline \multirow[b]{2}{*}{ Dyad } & \multirow{2}{*}{$\begin{array}{c}\text { Slope loading } \\
\text { at } \mathrm{T}^{\mathrm{a}}\end{array}$} & \multicolumn{2}{|c|}{ Intercept } & \multicolumn{2}{|c|}{ Slope } \\
\hline & & $M$ & $\sigma^{2}$ & $M$ & $\sigma^{2}$ \\
\hline FM & 1.4 & $4.32 * *$ & $.10 * *$ & $-.04 * *$ & $.01 * *$ \\
\hline FO & 1.9 & $4.06 * *$ & $.10 * *$ & -.03 & .01 \\
\hline FY & 1.7 & $4.08 * *$ & $.09 * *$ & $-.06^{* *}$ & .01 \\
\hline MF & 1.3 & $4.36 * *$ & $.09 * *$ & $-.07 * *$ & .02 \\
\hline MO & 1.2 & $4.09 * *$ & $.09 * *$ & $-.06 * *$ & .01 \\
\hline MY & 1.4 & $4.10 * *$ & $.07 * *$ & $-.06^{* *}$ & .01 \\
\hline $\mathrm{OF}$ & 2.3 & $4.07 * *$ & $.20 * *$ & -.03 & .02 \\
\hline OM & 1.3 & $4.11^{* *}$ & $.16^{* *}$ & -.02 & .04 \\
\hline OY & 2.2 & $3.88^{* *} *$ & $.17 * *$ & .01 & .02 \\
\hline YF & 1.3 & $4.11^{* *}$ & $.16^{* *}$ & -.02 & $.04 * *$ \\
\hline YM & 1.4 & $4.16^{* *}$ & $.15^{* *}$ & -.02 & $.04 * *$ \\
\hline YO & 1.6 & $3.86 * *$ & $.20 * *$ & $.05 * *$ & $.04 * *$ \\
\hline
\end{tabular}

Note. $\mathrm{T}=$ time; $\mathrm{FM}=$ support that father perceives from mother; $\mathrm{FO}=$ support that father perceives from the older child, FY = support that father perceives from the younger child, MF = support that mother perceives from father, and so on.

${ }^{\mathrm{a}} \mathrm{T} 1=0, \mathrm{~T} 2=1$ for all dyads.

$* * p<.01$. 
Table 3

Univariate Latent Growth Curve Results for Big Five Personality Characteristics

\begin{tabular}{|c|c|c|c|c|c|}
\hline \multirow[b]{2}{*}{ Big Five factor } & \multirow{2}{*}{$\begin{array}{l}\text { Slope loading } \\
\text { at } \mathrm{T}^{\mathrm{a}}\end{array}$} & \multicolumn{2}{|c|}{ Intercept } & \multicolumn{2}{|c|}{ Slope } \\
\hline & & $M$ & $\sigma^{2}$ & $M$ & $\sigma^{2}$ \\
\hline \multicolumn{6}{|l|}{ Extraversion } \\
\hline $\mathrm{F}$ & 2.3 & $4.95^{* *}$ & $.52 * *$ & .00 & .01 \\
\hline M & 1.6 & $5.12 * *$ & $.38^{* *}$ & .03 & .02 \\
\hline $\mathrm{O}$ & 1.9 & $4.90 * *$ & $.48 * *$ & .03 & .02 \\
\hline $\mathrm{Y}$ & 1.5 & $5.03 * *$ & $.55^{* *}$ & .00 & .02 \\
\hline \multicolumn{6}{|l|}{ Agreeableness } \\
\hline $\mathrm{F}$ & -0.4 & $5.64 * *$ & $.16^{* *}$ & -.01 & .00 \\
\hline M & 0.1 & $5.84 * *$ & $.10 * *$ & $-.09 * *$ & .00 \\
\hline $\mathrm{O}$ & 2.0 & $5.48 * *$ & $.17 * *$ & .03 & .01 \\
\hline $\mathrm{Y}$ & 1.7 & $5.51 * *$ & $.22^{* *}$ & .02 & .02 \\
\hline \multicolumn{6}{|l|}{ Conscientiousness } \\
\hline $\mathrm{F}$ & 1.2 & $4.96 * *$ & $.59 * *$ & .03 & .04 \\
\hline M & 1.0 & $4.92 * *$ & $.43 * *$ & $.32 * *$ & $.07 * *$ \\
\hline $\mathrm{O}$ & 1.9 & $4.15^{* *}$ & $.78^{* *}$ & .05 & $.05^{* *}$ \\
\hline $\mathrm{Y}$ & 1.5 & $4.03 * *$ & $.84 * *$ & .04 & .04 \\
\hline \multicolumn{6}{|l|}{ Emotional Stability } \\
\hline $\mathrm{F}$ & 2.3 & $4.85 * *$ & $.34 * *$ & -.01 & .01 \\
\hline M & 1.2 & $4.42 * *$ & $.39 * *$ & -.04 & .02 \\
\hline $\mathrm{O}$ & 1.3 & $4.63 * *$ & $.32 * *$ & .00 & .03 \\
\hline $\mathrm{Y}$ & -0.9 & $4.53 * *$ & $.32 * *$ & $-.04 * *$ & -.02 \\
\hline \multicolumn{6}{|l|}{ Openness } \\
\hline $\mathrm{F}$ & 2.2 & $4.63 * *$ & $.46 * *$ & .03 & .02 \\
\hline M & 1.7 & $4.71 * *$ & $.38 * *$ & .04 & $.04 * *$ \\
\hline $\mathrm{O}$ & 1.7 & $4.80 * *$ & $.41^{* *}$ & $.06 * *$ & $.04 * *$ \\
\hline $\mathrm{Y}$ & 1.6 & $4.91 * *$ & $.39 * *$ & .01 & .01 \\
\hline
\end{tabular}

Note. $\mathrm{T}=$ time; $\mathrm{F}=$ father's personality; $\mathrm{M}=$ mother's personality; $\mathrm{O}=$ older child's personality; $\mathrm{Y}=$ younger child's personality.

${ }^{\mathrm{a}} \mathrm{T} 1=0, \mathrm{~T} 2=1$ for all factors.

$* * p<.01$

decrease from Time 2 to Time 3 than from Time 1 to Time 2 (note that the direction of the change is indicated by the sign of the slope mean estimate).

The slope mean estimates of the univariate growth curve analyses for each of the dyadic support perceptions across the three measurement waves showed whether significant mean-level change in perceived support occurred over time (see Table 2, seventh column). In five of the dyadic family relationships, family members' mean levels of perceived support showed a declining trajectory over a 2-year period. Both fathers and mothers perceived, on average, less support over time from their partner, their older child, and their younger child. Only the adolescents did not show a decline in perceived support over time. In fact, the perceived support of the younger from their older siblings revealed a significant increase from the first to the last measurement wave. The older and younger adolescents did not significantly change on average in perceived support from their fathers and their mothers over time.

The slope estimates of the univariate growth curve analyses for each Big Five factor across the three measurement waves revealed that the mean Big Five factor scores were mostly constant over time (see Table 3, third column). The slope factor mean departs significantly from $0(p<.01)$ for mothers' Agreeableness and Conscientiousness, older adolescents' Openness to Experience and younger adolescents' Emotional Stability. Mothers revealed a significant average decrease in Agreeableness and increase in Con- scientiousness. Older adolescents increased in Openness to Experience, and younger adolescents showed a decrease in scores for Emotional Stability over a 2-year period.

The slope factor variance was significantly different from zero $(p<.01)$ only for the perceived support by younger adolescents, the perceived support by fathers from mothers, and for mothers' and older adolescents' Conscientiousness and Openness to Experience (see Tables 2 and 3, sixth column). This means that there were systematic individual differences in younger adolescents across families in the rate of change in support perceived from fathers, mothers, and older adolescents, and that mothers and older adolescents mostly differed across families in their changes on Conscientiousness and Openness to Experience.

\section{Multivariate Growth Curve Models}

The results of the multivariate growth curve models are presented in Tables 4 and $5 .{ }^{1}$ Even though we did not attempt to optimize fit, the fit of these 30 models to the data was acceptable to good, with chi-square ranging from 56.85 to 365.02 , and a mean of 113.50 for models with 44 degrees of freedom $(N=270), p<$ .001 , GFI ranging from .88 to .97 with a mean of .95 , the NNFI ranging from .77 to .99 with a mean of .95 , and the RMSEA ranging from .03 to .14 with a mean of .07 .

\section{Contemporary Correlations Between Big Five Factors and Perceived Relational Support}

The correlations between the intercepts of perceived relational support and Big Five factors of dyad members in adolescents' families are shown in Table $4 .^{2}$ The results clearly show that the Agreeableness of both dyadic partners is strongly and positively associated with the support perceived by each dyadic partner. Individuals who are more agreeable tend to perceive more support from their family members (intrapersonal associations) and are also perceived as more supportive than individuals who are less agreeable (interpersonal associations). The interpersonal correlations of Agreeableness and perceived support (i.e., the correlation between perceived support and the Big Five factors of the partner) were slightly higher than the intrapersonal correlations (i.e., the correlation between perceived support and the Big Five factors of the perceiver). For the other Big Five factors, correlations were less high and less consistent across family dyads. For Conscientiousness, significant intrapersonal correlations were found for all family members, whereas only a few significant interpersonal correlations were found. Thus, family members' Conscientious-

\footnotetext{
${ }^{1}$ We do not present the correlations between intercepts and slopes among the Big Five factors of the two relationship partners or among their support perceptions, because the focus of our study is on links between Big Five and perceived support. These results are available on request from the authors.

${ }^{2}$ To check for possible gender effects, we computed Wave 1 correlations for boys and girls separately on the domain of Agreeableness. Results did not differ widely from our findings for both sexes together. This may be related to the fact that differences in mean levels do not necessarily affect differences in relations between variables. For example, even though girls may be more agreeable than boys, differences among girls and among boys in agreeableness may be related to differences in their support perceptions.
} 
Table 4

Contemporary Relations Between Family Members' Perceived Support and Their Own (Perceiver) and Their Partners' Big Five Factors

\begin{tabular}{|c|c|c|c|c|c|c|c|c|c|c|c|c|}
\hline Dyad & FM & FO & FY & MF & $\mathrm{MO}$ & MY & OF & $\mathrm{OM}$ & OY & YF & YM & YO \\
\hline \multicolumn{13}{|l|}{ Extraversion } \\
\hline Intrapersonal & $.28 * *$ & $.26 * *$ & $.24 * *$ & $.23^{* *}$ & $.29 * *$ & $.29 * *$ & .02 & .06 & $.20 * *$ & .15 & .17 & $.27 * *$ \\
\hline Interpersonal & .06 & .05 & .17 & $.27 * *$ & .06 & .17 & .17 & $.29 * *$ & $.25 * *$ & $.23^{* *}$ & $.33 * *$ & .17 \\
\hline \multicolumn{13}{|l|}{ Agreeableness } \\
\hline Intrapersonal & $.32 * *$ & $.39 * *$ & $.38 * *$ & $.40 * *$ & $.46^{* *}$ & $.45^{* *}$ & $.43 * *$ & $.42 * *$ & $.44 * *$ & $.36^{* *}$ & $.40^{* *}$ & $.52 * *$ \\
\hline Interpersonal & $.50 * *$ & $.43 * *$ & $.44 * *$ & $.49 * *$ & $.52 * *$ & $.44 * *$ & $.50 * *$ & $.45 * *$ & $.61 * *$ & $.27 * *$ & $.38^{* *}$ & $.59 * *$ \\
\hline \multicolumn{13}{|c|}{ Conscientiousness } \\
\hline Intrapersonal & $.33 * *$ & $.22^{* *}$ & $.19^{* *}$ & $.19^{* *}$ & $.20^{* *}$ & $.26^{* *}$ & $.36^{* *}$ & $.33 * *$ & $.24 * *$ & $.28 * *$ & $.19^{* *}$ & $.19 * *$ \\
\hline Interpersonal & $.28 * *$ & $.25^{* *}$ & .12 & .14 & $.38^{* *}$ & $.29 * *$ & .08 & .11 & .09 & .22 & -.03 & .17 \\
\hline \multicolumn{13}{|c|}{ Emotional Stability } \\
\hline Intrapersonal & $.21 * *$ & $.28^{* *}$ & .15 & $.23^{* *}$ & $.25^{* *}$ & $.26^{* *}$ & $.23 * *$ & .14 & $.27 * *$ & .18 & .16 & .18 \\
\hline Interpersonal & $.21 * *$ & $.29^{* *}$ & .07 & $.30^{* *}$ & $.26^{* *}$ & .19 & $.24 * *$ & $.28 * *$ & $.20 * *$ & .17 & $.34 * *$ & $.26^{* *}$ \\
\hline \multicolumn{13}{|c|}{ Openness to Experience } \\
\hline Intrapersonal & .12 & $.25^{* *}$ & $.28 * *$ & .11 & $.19^{* *}$ & $.30 * *$ & .15 & .08 & $.22 * *$ & .17 & .17 & $.23 * *$ \\
\hline Interpersonal & $.22 * *$ & .14 & $.26 * *$ & .18 & .12 & .24 & $.27 * *$ & .07 & $.22 * *$ & .11 & .14 & .14 \\
\hline
\end{tabular}

Note. $\quad \mathrm{FM}=$ support that father perceives from mother, $\mathrm{FO}=$ support that father perceives from the older child, $\mathrm{FY}=$ support that father perceives from the younger child, $\mathrm{MF}=$ support that mother perceives from father, and so on.

$* * p<.01$

ness is more important for their support perceptions than the Conscientiousness of their relationship partners. For the other dimensions, interpersonal and intrapersonal correlations were found to a roughly equal extent. Lowest correlations were observed for Openness to Experience.

\section{Over-Time Intercept-Slope Correlations}

The correlation between dyad members' intercepts and slopes of the Big Five and perceived support was examined to test whether individual differences in personality or perceived support at Time 1 predicted individual differences in the rate of change in personality or perceived support from Time 1 to Time 3 .
Some significant intercept-slope correlations were found between Big Five factors and perceived support of dyad members after applying a Bonferroni correction. We did not find evidence for effects of a dyad member's initial level of perceived support on any changes in Big Five factors of that dyad member (intrapersonal) over time. As expected, a dyad member's Big Five factors significantly predicted changes in the other dyad member's perceived support, but only in two instances. An interpersonal effect appeared for Agreeableness: Fathers' initial level of Agreeableness predicted changes in the support that the younger adolescents perceived from fathers (.57). This means that younger adolescents whose father had higher initial levels of Agreeableness tended to

Table 5

Concomitant Change Between Family Members' Perceived Support and Their Own (Intrapersonal) and Their Partners' Big Five Factors

\begin{tabular}{|c|c|c|c|c|c|c|c|c|c|c|c|c|}
\hline Dyad & FM & FO & FY & MF & MO & MY & $\mathrm{OF}$ & $\mathrm{OM}$ & OY & YF & YM & YO \\
\hline \multicolumn{13}{|l|}{ Extraversion } \\
\hline Intrapersonal & .29 & .21 & .48 & .02 & $.82 * *$ & .51 & .24 & .14 & .22 & $.66^{* *}$ & .53 & .38 \\
\hline Interpersonal & .53 & $.61 * *$ & .18 & $.60^{* *}$ & $.88 * *$ & .55 & $.60 * *$ & .37 & $.56^{* *}$ & .41 & $.52 * *$ & .22 \\
\hline \multicolumn{13}{|l|}{ Agreeableness } \\
\hline Intrapersonal & -.22 & -.17 & $-.12 * *$ & .02 & .02 & -.01 & $.45 * *$ & $.61 * *$ & $.55^{* * *}$ & $.44 * *$ & .25 & $.42 * *$ \\
\hline Interpersonal & .04 & $.60 * *$ & .36 & -.08 & $1.36^{* * a}$ & $.79 * *$ & -.21 & .06 & $.61^{* *}$ & -.19 & -.03 & $.95^{* *}$ \\
\hline \multicolumn{13}{|c|}{ Conscientiousness } \\
\hline Intrapersonal & $.99 * *$ & $.49 * *$ & .45 & .08 & .06 & .19 & $.52 * *$ & $.57 * *$ & $.45^{* *}$ & .33 & .14 & .19 \\
\hline Interpersonal & .33 & .33 & .29 & $.49^{* *}$ & .49 & .41 & .31 & .30 & .18 & .19 & .13 & $.40 * *$ \\
\hline \multicolumn{13}{|c|}{ Emotional Stability } \\
\hline Intrapersonal & .05 & .24 & .35 & .18 & .60 & .71 & .36 & .40 & .49 & $-.06^{* *}$ & -.04 & $-.06^{* *}$ \\
\hline Interpersonal & .26 & .19 & -.01 & .38 & $.88 * *$ & -.04 & .34 & .43 & .01 & .19 & $.85^{* *}$ & .35 \\
\hline \multicolumn{13}{|c|}{ Openness to Experience } \\
\hline Intrapersonal & $.53 * *$ & $.60 * *$ & $.61 * *$ & .07 & .22 & .22 & $.42 * *$ & $.41 * *$ & .34 & .23 & .22 & $.52 * *$ \\
\hline Interpersonal & $.47 * *$ & $.50 * *$ & .23 & .36 & $.80 * *$ & .26 & $.50 * *$ & $.40 * *$ & .31 & .11 & $.30 * *$ & $.52 * *$ \\
\hline
\end{tabular}

Note. $\quad \mathrm{FM}=$ support that father perceives from mother, $\mathrm{FO}=$ support that father perceives from the older child, $\mathrm{FY}=$ support that father perceives from the younger child, $\mathrm{MF}=$ support that mother perceives from father, and so on.

${ }^{a}$ This is $>1$ because, as Jöreskog (1999) described, these are structural coefficients and can incidentally be larger than 1 in magnitude in the completely standardized solution.

$* * p<.01$. 
report higher rates of change in support perceived from father over time. An intrapersonal effect appeared for Openness: Fathers' higher initial level of Openness to Experience predicted lower rates of decrease in the support that fathers perceived from older adolescents (-.38). These results on over-time correlations for Big Five factors to perceived support and vice versa suggest that Big Five factors are indeed more predictive of changes in relationship qualities than vice versa.

\section{Concomitant Change in Big Five Factors and Perceived Support}

Correlations between slopes of the Big Five factors and perceived support of dyad members were investigated to test whether changes in family members' Big Five factors are related to changes in the support they perceive (intrapersonal relation) and whether changes in family members' Big Five factors are related to changes in the support perceived from them (interpersonal relation). The results are presented in Table 5. This table shows that most concomitant change, both intrapersonal and interpersonal, appeared for Agreeableness and Openness to Experience. Furthermore, for Agreeableness, intrapersonal correlations mainly appeared for adolescents' perceptions of support. More interpersonal than intrapersonal correlations were found for Extraversion, whereas more intrapersonal than interpersonal correlations were found for Conscientiousness.

\section{Discussion}

This longitudinal study examined relations between Big Five factors and a specific element of relationships (i.e., perceived support) in adolescents' families. It took the important step of examining how changes in Big Five factors are tied to changes in perceptions of support. Overall, the results showed considerable stability in the life of families with two parents and (at least) two adolescent children, supporting the idea of parallel continuities between personality and perceived support. The few significant slope means and variances in the LGMs, as well as the high percentages of family members revealing no reliable individual change, indicated that the Big Five factors are highly stable over a 2-year period. Although perceived support was also stable for many individual family members, perceived support tended to change more during adolescence than personality. The high level of stability in the present study compared with other studies may be due to the shorter period under investigation in our study. Also, the combining of multiple well-informed sources (i.e., self and three family members) may have resulted in more robust and consistent measures for the Big Five factors.

Although the RCIs revealed that the probability of someone changing a great deal in Big Five factors and perceived support during this developmental period was rather small, they also revealed that some individual family members did change in Big Five factors and in perceived support. Despite the few significant slope variances, a certain number of individual family members did change to a significant degree on each Big Five factor and on support perceptions in all family dyads, over and above randomly expected change. In addition, several significant slope means indicated mean level changes, and several significant slope variances indicated individual variability in the rate of change over time. Thus, our results indicate quite clearly that change does occur in family members' Big Five factors and dyadic support perceptions, even over a relatively short period of 2 years, and the results allow for an examination of relations between change in support and personality.

There appear to be parallel continuities for the relations between Big Five factors and perceptions of support. Contemporary relations between Big Five factors and perceived relational support were found most frequently. These contemporary associations appeared both intra- and interpersonally and were strongest for Agreeableness. Over time, personality and support hardly seemed to influence each other: Change in support could only incidentally be attributed to interindividual differences in specific personality characteristics, and change in personality characteristics was not caused by interindividual differences in support experiences. However, interindividual differences in change in Big Five factors were found to be related to interindividual differences in changes in relationships. Although changes in personality and support perceptions were generally small, they often tended to change together. This concomitant change may be due to the changes in relationships or the change in personality characteristics but could also be caused by other factors, such as significant life events or turning points (see Vaidya, Gray, Haig, \& Watson, 2002). Although the period of adolescence is not particularly stressful for most adolescents and their family members, for some it may be a challenge to their relationships. We expect that behavioral changes during adolescence, such as youthful experimentation or increasing autonomy, may lead to changes in personality or family relationships. Also, it could be that those few families who shift on personality or support may be going through a particularly difficult period, such as the death of an important loved one, or the loss of job by a parent. Once these difficulties pass, things may return to their baseline levels. In addition, concomitant change may also be due to normative developmental changes in support and personality: Support generally decreases somewhat in relationships of families with adolescents (Furman \& Buhrmester, 1985). During adulthood, Extraversion, Emotional Stability, and Openness to Experience decrease, while Agreeableness and Conscientiousness increase (McCrae et al., 2000; Srivastava, John, Gosling, \& Potter, 2003). During adolescence, Emotional Stability and Openness to Experiences tend to increase (McCrae et al., 2002). In any case, what is important from a theoretical perspective is the fact that individual differences in rate of change in Big Five factors and individual differences in rate of change in perceived support are meaningfully related. Big Five factors appear to be neither an unchangeable temperament (McCrae et al., 2000) nor prone to change depending on the context (Lewis, 1999). However, Big Five factors are not easily affected by relationship experiences (Asendorpf \& van Aken, 2003).

The support that fathers and mothers perceived from family members significantly decreased over time. The finding of declines in perceived support in the parent-child relationship during early and middle adolescence is not surprising. One possible interpretation of this is that parents have difficulties granting their adolescents more autonomy, resulting in decreasing perceived support from their children as they get older. More surprising is the lack of significant changes for adolescents' perceived support from parents. The support that younger adolescents perceived from their siblings significantly increased over time. These increases in sibling support are consistent with conceptions of the older sibling's role as that of leader and with the findings of research on sibling 
relationships which suggests that older sisters and brothers are a particularly important source of advice and guidance in early adolescence about issues having to do with school, the peer group, or risky behavior-issues about which parents may have much less credibility (Tucker, McHale, \& Crouter, 2001).

Generally, our results suggest that reciprocal influences between Big Five factors and support are established early in the relationship and remain stable throughout the course of the relationship. These results support the contentions of the parallel continuities hypothesis, which implies that individual behaviors may remain stable when there is concomitant stability in the environment (Caspi, 1993, 2000; Halverson \& Wampler, 1997; Patterson \& Bank, 1989). The lack of over-time effects found in the present study may be the result of cumulative and continuing continuities of individual differences in personality characteristics and supportive environments. Stable personality characteristics promote stability in supportive relationships, and stable supportive relationships promote stability in individual characteristics. These findings are also consistent with the enduring-dynamics model, which posits that initial differences in relationships persist and predict the long-term status of the relationship (Huston, Caughlin, et al., 2001; Huston, Niehuis, \& Smith, 2001). Although this model was formulated in the context of marital relationships, our results suggest that it may equally apply to other family relationships.

Only two over-time effects between individual differences in Big Five factors and change in perceived support were found, and both effects concerned fathers' personality characteristics and the relationship of fathers with one of their children. One of these two effects was an interpersonal effect on the support perceived by children, the other effect was an intrapersonal effect on the support perceived by fathers themselves. Both effects were Big Five factor $\rightarrow$ support transactions rather than support $\rightarrow$ Big Five factor transactions, although it should be noted that there were only half as many possibilities for the latter to arise in the data. Overall, no consistent over-time effects were found, but this fact might be attributable to the fact that we studied only family relationships. Family relationships have a long history, and a personalityrelationship fit may already have been established before the study began. In contrast, Asendorpf and Wilpers (1998) and Neyer and Asendorpf (2001), who found a stronger dominance for personality effects on relationships, reported these effects mainly for peer relationships that may be more open to influences from personality because of their discontinuity and change. Moreover, Asendorpf and Wilpers studied students in the period after university entrance, which is a period of tremendous changes.

In the context of families with adolescent children, family members' Agreeableness seems most strongly linked to both the support they perceive and the support that is perceived from them. Contemporary intrapersonal and interpersonal associations between personality and perceived relational support were strongest and most consistent for Agreeableness. Moreover, slope correlations showed changes in perceived support to be mostly related to changes in both Agreeableness and Openness to Experience. These results suggest that Agreeableness is the Big Five factor most closely related to perceived support in family relationships. One could argue that the concepts of agreeableness and support are comparable and might both have been an assessment of being helpful. There are, however, several arguments against this suggestion. For example, perceived support is assessed in terms of concrete behavior, whereas personality is assessed in terms of general traits. In addition, receiving support may have detrimental effects when the support is perceived as intrusive and a sign that the person is not capable of handling things him- or herself (Gleason, Iida, Bolger, \& Shrout, 2003), which implies that even "nice" people may provide support too often or too soon. In contrast to measures of social support, our perceived relational support questionnaire explicitly asks for the extent to which others let the perceiver handle problems by him- or herself and only support the perceiver when asked to do so. Also, the instrument assesses not only emotional support and helpful behavior but also openness of communication and agreement on motives and goals. These aspects of relational support may have relations to other personality factors than Agreeableness. Research generally has shown the personality factors Emotional Stability and Extraversion to be more important, especially in marital relationships, even though the argument that "nice" people have better relationships may apply to all measures of relationship quality. And lastly, Reynolds and Karraker (2003) showed that Agreeableness is not related to providing support in all circumstances: In situations in which people are in a hurry, the factor Conscientiousness is related to being supportive.

We did not find equally strong evidence that Conscientiousness was related to perceived support in family relationships. Family members' Conscientiousness was predominantly and positively linked to their own perceptions of support, but not to the support perceived from them by their relationship partners. Perhaps this difference between intrapersonal and interpersonal links reflects the effect of Conscientiousness on evaluating other people's behavior: Whereas conscientious individuals may be more attentive to others' behavior toward them, less conscientious individuals may tend to disregard these behaviors. Although more conscientious individuals may also be more supportive toward others, our results suggest that this support does not have to be perceived as such by their relationship partners.

Contrary to expectation, Extraversion and Emotional Stability were not found to be more important in the marital relationship than in other relationships. However, parents' Extraversion appeared to be more important to perceived support than adolescents' Extraversion: Parents' Extraversion was significantly related to their own perceived support and to the support perceived from them by their children (except for older adolescents' support from father). The relevance of Extraversion in earlier studies may therefore be more an effect of age than of relationship type. Similarly, Emotional Stability was moderately linked to support in many relationships, but this was least marked for relationships involving the younger child. Openness to Experience seemed especially related to support perceived from children, both in the parentchild and in the sibling relationship, and may therefore be important for support in relationships in which providing support is less normative. Family members who are more open to experiences may have less difficulties accepting behavioral experimentation of adolescents, and consequently perceive less deterioration of the relationship with these adolescents. These differences across relationships remind us that associations between Big Five factors and relationship experiences do not have to apply to all family relationships to the same extent, and they reaffirm the importance of examining relations between Big Five factors and relationship separately in multiple types of relationships within the same family. 


\section{Strengths of the Study}

Among the strengths of this study was that we were able to study all family relationships, because we assessed personality and support simultaneously from all four members of two-parent, two-adolescent families. The longitudinal data made it possible to study personality-family relationship transactions more reliably using growth curve modeling and with more methodological rigor because of the reliability of the individual change scores. The latent growth curve models included both intrapersonal and interpersonal relations between personality and support, thereby controlling for the interdependence of dyadic partners. By using multiple judgments (self- and other-judgments), intrapersonal and interpersonal effects were equally enhanced. Also, by using multivariate growth curve analyses, shared method variance is reduced because the error is partly eliminated by the indirect effects (see Neyer \& Asendorpf, 2001). These features give us greater confidence that, although for most family members Big Five factors remain stable over time, there are family members who reveal reliable and meaningful patterns of change in Big Five factors and support. Furthermore, LGM enables us to examine over-time relations while controlling for the contemporary relations between Big Five factors and perceived support at Time 1, and vice versa. This methodology is therefore appropriate to disentangle the effects of Big Five factors and perceived support on each other, although it should be noted that these analyses do not provide conclusive evidence for a causal effect of Big Five factors on support.

\section{Limitations and Future Directions}

Despite these strengths, the study is limited by its focus on dyadic family relationships. This study stresses the importance of both partners in dyadic family relationships, but the context of other relationships within the family may influence the pattern of bidirectional effects in the dyadic relationship (Dunn, 1997). For example, evidence has been found for a spillover effect of the marital relationship on the parent-child relationship (Cummings \& Davies, 2002; Davies, Harold, Goeke-Morey, \& Cummings, 2002; Erel \& Burman, 1995), and the marital relationship can also influence the sibling relationship by affecting the parent-child relationship (Brody, 1998). The present study indeed showed that change in personality or support of one family member relates to change in personality or support of other family members, but it is not clear from these results whether all relationships are equally likely to influence all other relationships or whether some relationships (e.g., the marital relationship) are more influential or more resistant to change than others. Future research might address these issues further.

Another limitation concerns the sample characteristics in the present study. The sample consisted of two-parent, middle-class, native families in the Netherlands, and the results of this study can only be generalized to families with these characteristics. We cannot conclude that the results can be generalized to families with other characteristics, such as single-parent families, adoptive or stepfamilies, or families from different ethnic origins. Other studies should investigate whether the present results can be replicated in families with other characteristics.

Taken together, there are some important lessons to be learned from this study. First, even though Big Five factors scores are stable over time for the sample as a whole, subgroups of individuals who display distinct and reliable patterns of change can be identified. Second, individual differences in Big Five factors were more likely to influence changes in support than vice versa. Agreeableness appeared as the one Big Five factor most related to changes in relationships. And finally, within adolescents' dyadic family relationships at least, there is a co-occurrence of change in Big Five factors and perceptions of support by individual family members.

\section{References}

Asendorpf, J. B., \& van Aken, M. A. G. (2003). Personality-relationship transaction in adolescence: Core versus surface personality characteristics. Journal of Personality, 71, 629-666.

Asendorpf, J. B., \& Wilpers, S. (1998). Personality effects on social relationships. Journal of Personality and Social Psychology, 74, 15311544.

Bell, R. Q., \& Chapman, M. (1986). Child effects in studies using experimental or brief longitudinal approaches to socialization. Developmental Psychology, 22, 595-603.

Bentler, P. M. (1990). Comparative fit indices in structural models. Psychological Bulletin, 107, 238-246.

Bloom, B. L. (1985). A factor analysis of self-report measures of family functioning. Family Process, 24, 225-239.

Bowes, J. M., Flanagan, C., \& Taylor, A. J. (2001). Adolescents' ideas about individual and social responsibility in relation to children's household work: Some international comparisons. International Journal of Behavioral Development, 25, 60-68.

Branje, S. J. T., van Aken, M. A. G., Van Lieshout, C. F. M., \& Mathijssen, J. J. J. P. (2003). Personality judgments in adolescents' families: The perceiver, the target, their relationship, and the family. Journal of Personality, 71, 49-81.

Brody, G. H. (1998). Sibling relationship quality: Its causes and consequences. Annual Review of Psychology, 49, 1-24.

Browne, M. W., \& Cudeck, R. (1989). Single sample cross-validation indices for covariance structures. Multivariate Behavioral Research, 24, $445-455$.

Browne, M. W., \& Cudeck, R. (1993). Alternative ways of assessing model fit. In K. A. Bollen \& J. S. Long (Eds.), Testing structural equation models (pp. 132-162). Beverly Hills, CA: Sage.

Caspi, A. (1993). Why maladaptive behaviors persist: Sources of continuity and change across the life course. In D. C. Funder \& R. D. Parke (Eds.), Studying lives through time: Personality and development (pp. 343-376). Washington, DC: American Psychological Association.

Caspi, A. (1998). Personality development across the life course. In W. Damon (Ed.), Handbook of child psychology (5th ed., Vol. 3, pp. 311-388). New York: Wiley.

Caspi, A. (2000). The child is father of the man: Personality continuities from childhood to adulthood. Journal of Personality and Social Psychology, 78, 158-172.

Caspi, A., \& Roberts, B. W. (1999). Personality change and continuity across the life course. In L. A. Pervin \& O. P. John (Eds.), Handbook of personality theory and research (pp. 300-326). New York: Guilford Press.

Caspi, A., \& Roberts, B. W. (2001). Target article: Personality development across the life course: The argument for change and continuity. Psychological Inquiry, 12, 49-66.

Caughlin, J. P., Huston, T. L., \& Houts, R. M. (2000). How does personality matter in marriage? An examination of trait anxiety, interpersonal negativity, and marital satisfaction. Journal of Personality and Social Psychology, 78, 326-336.

Christensen, L., \& Mendoza, J. L. (1986). A method of assessing change in a single subject: An alteration of the RC index. Behavior Therapy, 17, 305-308. 
Collins, W. A., Maccoby, E. E., Steinberg, L., Hetherington, E. M., \& Bornstein, M. H. (2000). Contemporary research on parenting: The case for nature and nurture. American Psychologist, 55, 218-232.

Conner, M., \& Abraham, C. (2001). Conscientiousness and the theory of planned behavior: Toward a more complete model of the antecedents of intentious behavior. Personality and Social Psychology Bulletin, 27, $1547-1561$.

Cummings, E. M., \& Davies, P. T. (2002). Effects of marital conflict on children: Recent advances and emerging themes in process-oriented research. Journal of Child Psychology and Psychiatry and Allied Disciplines, 43, 31-63.

Cutrona, C. E., Hessling, R. M., \& Suhr, J. A. (1997). The influence of husband and wife personality on marital social support interactions. Personal Relationships, 4, 379-393.

Davies, P. T., Harold, G. T., Goeke-Morey, M. C., \& Cummings, E. M. (2002). Child emotional security and interparental conflict. Monographs of the Society for Research in Child Development, 67(3, Serial No. 270).

Duncan, S. C., Duncan, T. E., \& Strycker, L. A. (2001). Qualitative and quantitative shifts in adolescent problem behavior development: A cohort-sequential multivariate latent growth modeling approach. Journal of Psychopathology and Behavioral Assessment, 23, 43-50.

Dunn, J. (1997). Lessons from the study of bidirectional effects. Journal of Social and Personal Relationships, 14, 565-573.

Erel, O., \& Burman, B. (1995). Interrelatedness of marital relations and parent-child relations: A meta-analytic review. Psychological Bulletin, $18,108-132$

Furman, W., \& Buhrmester, D. (1985). Children's perceptions of the personal relationships in their social networks. Developmental Psychology, 21, 1016-1024.

Gerris, J. R. M., Houtmans, M. J. M., Kwaaitaal-Roosen, E. M. G., Schipper, J. C., Vermulst, A. A., \& Janssens, J. M. A. M. (1998). Parents, adolescents, and young adults in Dutch families: A longitudinal study. Nijmegen, the Netherlands: University of Nijmegen, Institute of Family Studies.

Gleason, M. E. J., Iida, M., Bolger, N., \& Shrout, P. E. (2003). Daily supportive equity in close relationships. Personality and Social Psychology Bulletin, 29, 1036-1045.

Goldberg, L. R. (1992). The development of markers of the Big-Five factor structure. Psychological Assessment, 4, 26-42.

Griffin, D., \& Gonzalez, R. (1995). Correlational analysis of dyad-level data in the exchangeable case. Psychological Bulletin, 118, 430-439.

Halverson, C. F., \& Wampler, K. S. (1997). Family influences on personality development. In R. Hogan, J. A. Johnson, \& S. R. Briggs (Eds.), Handbook of personality psychology (pp. 241-267). San Diego, CA: Academic Press.

Hamagami, F., \& McArdle, J. J. (2001). Advanced studies of individual differences linear dynamic models for longitudinal data analysis. In G. A. Marcoulides \& R. E. Schumacker (Eds.), New developments and techniques in structural equation modeling (pp. 203-246). Mahwah, NJ: Erlbaum.

Haselager, G. J. T., \& van Aken, M. A. G. (1999). Codebook of the research project Family and Personality: Vol. 1. First measurement wave. Nijmegen, the Netherlands: University of Nijmegen, Faculty of Social Science.

Hogan, J., \& Ones, D. S. (1997). Conscientiousness and integrity at work. In R. Hogan, J. A. Johnson, \& S. R. Briggs (Eds.), Handbook of personality psychology (pp. 849-870). San Diego, CA: Academic Press.

Holmbeck, G. H., Paikoff, R. L., \& Brooks-Gunn, J. (1995). Parenting adolescents. In M. Bornstein (Ed.), Handbook of parenting: Vol. 1. Children and parenting (pp. 91-118). Mahwah, NJ: Erlbaum.

Hu, L. T., \& Bentler, P. M. (1999). Cut-off criteria for fit indexes in covariance structure analysis: Conventional criteria versus new alternatives. Structural Equation Modelling, 6, 1-55.

Huston, T. L., Caughlin, J. P., Houts, R. M., Smith, S., \& George, L. J. (2001). The connubial crucible: Newlywed years as predictors of marital delight, distress, and divorce. Journal of Personality and Social Psychology, 80, 237-252.

Huston, T. L., Niehuis, S., \& Smith, S. E. (2001). The early marital roots of conjugal distress and divorce. Current Directions in Psychological Science, 10, 116-119.

Jacobson, N. S., \& Truax, P. (1991). Clinical significance: A statistical approach to defining meaningful change in psychotherapy research. Journal of Consulting and Clinical Psychology, 59, 12-19.

Jensen-Campbell, L. A., \& Graziano, W. G. (2001). Agreeableness as a moderator of interpersonal conflict. Journal of Personality, 69, 323-362.

Jöreskog, K. G. (1999, June 22). How large can a standardized coefficient be? Available at http://www.ssicentral.com/lisrel/column2.htm

Jöreskog, K. G., \& Sörbom, D. (1996). LISREL 8: User's reference guide. Chicago: Scientific Software International.

Karney, B. R., \& Bradbury, T. N. (1995). Assessing longitudinal change in marriage: An introduction to the analysis of growth curves. Journal of Marriage and the Family, 57, 1091-1108.

Kenny, D. A. (1995). The effect of nonindependence on significance testing in dyadic research. Personal Relationships, 2, 67-75.

Kenny, D. A. (1996). Models of nonindependence in dyadic research. Journal of Social and Personal Relationships, 13, 279-294.

Kenny, D. A., \& Cook, W. (1999). Partner effects in relationship research: Conceptual issues, analytic difficulties, and illustrations. Personal Relationships, 6, 433-448.

Lakey, B., Ross, L. T., Butler, C., \& Bentley, K. (1996). Making social support judgments: The role of similarity and conscientiousness. Journal of Social and Clinical Psychology, 15, 283-304.

Laursen, B. (1995). Conflict and social interaction in adolescent relationships. Journal of Research on Adolescence, 5, 55-70.

Lewis, M. (1999). On the development of personality. In L. A. Pervin \& O. P. John (Eds.), Handbook of personality theory and research (pp. 327-346). New York: Guilford Press.

Lollis, S., \& Kuczynski, L. (1997). Beyond one hand clapping: Seeing bidirectionality in parent-child relations. Journal of Social and Personal Relationships, 14, 441-461.

Maccoby, E. E. (1984). Socialization and developmental change. Child Development, 55, 317-328.

Manetti, M., \& Schneider, B. H. (1996). Stability and change in patterns of parental social support and their relation to children's school adjustment. Journal of Applied Developmental Psychology, 17, 101-115.

McArdle, J. J., \& Bell, R. Q. (2000). An introduction to latent growth models for developmental data analysis. In T. D. Little, K. U. Schnabel, \& J. Baumert (Eds.), Modeling longitudinal and multilevel data: Practical issues, applied approaches, and specific examples (pp. 69-107, 269-281). Mahwah, NJ: Erlbaum.

McCrae, R. R., Costa, P. T., Jr., Ostendorpf, F., Angleitner, A., Hrebickova, M., Avia, M. D., et al. (2000). Nature over nurture: Temperament, personality, and life span development. Journal of Personality and Social Psychology, 78, 173-186.

McCrae, R. R., Costa, P. T., Jr., Terracciano, A., Parker, W. D., Mills, C. J., De Fruyt, F., \& Mervielde, I. (2002). Personality trait development from age 12 to age 18: Longitudinal, cross-sectional and cross-cultural analyses. Journal of Personality and Social Psychology, 83, 1456-1468.

McCrae, R. R., Stone, S. V., Fagan, P. J., \& Costa, P. T., Jr. (1998). Identifying causes of disagreement between self-reports and spouse ratings of personality. Journal of Personality, 66, 285-313.

Mehta, P. D., \& West, S. G. (2000). Putting the individual back into individual growth curves. Psychological Methods, 5, 23-43.

Meredith, W., \& Tisak, J. (1990). Latent curve analysis. Psychometrika, $55,107-122$.

Muthen, B. O. (1991). Analysis of longitudinal data using latent variable models with varying parameters. In L. M. Collins \& J. L. Horn (Eds.), Best methods for the analysis of change: Recent advances, unanswered questions, future directions (pp. 1-17). Washington, DC: American Psychological Association. 
Muthen, B. O., \& Curran, P. J. (1997). General longitudinal modeling of individual differences in experimental designs: A latent variable framework for analysis and power estimation. Psychological Methods, 2, 371-402.

Neyer, F. J., \& Asendorpf, J. B. (2001). Personality-relationship transaction in young adulthood. Journal of Personality and Social Psychology, 81, 1190-1204.

Olson, D. H. (1986). Circumplex Model VII: Validation studies and FACES III. Family Process, 25, 337-351.

Patterson, G. R., \& Bank, C. L. (1989). Some amplifying mechanisms for pathologic processes in families. In M. R. Gunnar \& E. Thelen (Eds.), The Minnesota symposia on child psychology: Vol. 22. Systems and development (pp. 167-209). Hillsdale, NJ: Erlbaum.

Rao, C. R. (1958). Some statistical models for comparison of growth curves. Biometrics, 14, 1-17.

Reis, H. T., Collins, W. A., \& Berscheid, E. (2000). The relationship context of human behavior and development. Psychological Bulletin, 126, 844-872.

Reynolds, B., \& Karraker, K. (2003). A Big Five model of disposition and situation interaction: Why a "helpful" person may not always behave helpfully. New Ideas in Psychology, 21, 1-13.

Roberts, B. W., Caspi, A., \& Moffitt, T. E. (2001). The kids are alright: Growth and stability in personality development from adolescence to adulthood. Journal of Personality and Social Psychology, 81, 670-683.

Roberts, B. W., \& DelVecchio, W. F. (2000). The rank-order consistency of personality from childhood to old age: A quantitative review of longitudinal studies. Psychological Bulletin, 126, 3-25.

Robins, R. W., Caspi, A., \& Moffitt, T. E. (2000). Two personalities, one relationship: Both partners' personality traits shape the quality of their relationship. Journal of Personality and Social Psychology, 79, 251259 .

Robins, R. W., Caspi, A., \& Moffitt, T. E. (2002). It's not just who you're with, it's who you are: Personality and relationship experiences across multiple relationships. Journal of Personality, 70, 925-964.

Robins, R. W., John, O. P., \& Capsi, A. (1994). Major dimensions of personality in early adolescence: The Big Five and beyond. In C. F. Halverson Jr. \& G. A. Kohnstamm (Eds.), The developing structure of temperament and personality from infancy to adulthood (pp. 267-291). Hillsdale, NJ: Erlbaum.

Russell, D. W., Booth, B., Reed, D., \& Laughlin, P. R. (1997). Personality, social networks, and perceived social support among alcoholics: A structural equation analysis. Journal of Personality, 65, 649-692.

Sameroff, A. J. (1983). Developmental systems: Contexts and evolution. In
W. Kessen (Ed.), Handbook of child psychology: Vol. 1. History, theory, and methods (4th ed., pp. 237-294). New York: Wiley.

Scholte, R. H. J., van Lieshout, C. F. M., \& van Aken, M. A. G. (2001). Perceived relational support in adolescence: Dimensions, configurations, and adolescent adjustment. Journal of Research in Adolescence, 11, 71-94.

Shaver, P. R., \& Brennan, K. A. (1992). Attachment styles and the "Big Five" personality traits: Their connections with each other and with romantic relationship outcomes. Personality and Social Psychology Bulletin, 18, 536-545.

Shiner, R. L., Tellegen, A., \& Masten, A. S. (2001). Exploring personality across childhood into adulthood: Can one describe and predict a moving target? Psychological Inquiry, 12, 96-100.

Srivastava, S., John, O. P., Gosling, S. D., \& Potter, J. (2003). Development of personality in early and middle adulthood: Set like plaster or persistent change? Journal of Personality and Social Psychology, 84, 1041-1053.

Steiger, J. H. (1990). Structural model evaluation and modification: An interval estimation approach. Multivariate Behavioral Research, 25, 173-180.

Stein, J. A., Newcomb, M. D., \& Bentler, P. M. (1986). Stability and change in personality: A longitudinal study from early adolescence to young adulthood. Journal of Research in Personality, 20, 276-291.

Tucker, C. J., McHale, S. M., \& Crouter, A. C. (2001). Conditions of sibling support in adolescence. Journal of Family Psychology, 15, 254 271.

Vaidya, J. G., Gray, E. K., Haig, J., \& Watson, D. (2002). On the temporal stability of personality: Evidence for differential stability and the role of life experiences. Journal of Personality and Social Psychology, 83, $1469-1484$

Van Lieshout, C. F. M. (2000). Life-span personality development: Selforganizing goal-oriented agents and developmental outcome. International Journal of Behavioral Development, 24, 276-288.

Watson, D., Hubbard, B., \& Wiese, D. (2000). General traits of personality and affectivity as predictors of satisfaction in intimate relationships: Evidence from self- and partner-ratings. Journal of Personality, 68, 413-449.

Weigel, D. J., Devereux, P., Leigh, G. K., \& Ballard-Reisch, D. (1998). A longitudinal study of adolescents' perceptions of support and stress: Stability and change. Journal of Adolescent Research, 13, 158-177.

Received March 25, 2003

Revision received November 14, 2003

Accepted November 17, 2003

\section{E-Mail Notification of Your Latest Issue Online!}

Would you like to know when the next issue of your favorite APA journal will be available online? This service is now available to you. Sign up at http://watson.apa.org/ notify/and you will be notified by e-mail when issues of interest to you become available! 